\title{
SPESIFIKASI KEBUTUHAN PERANGKAT LUNAK SISTEM INFORMASI AKADEMIK UNIVERSITAS MA CHUNG MALANG
}

\author{
Kharisma Dharma Pertiwi \\ Fakultas Sains dan Teknologi, Program Studi Sistem Informasi \\ Universitas Ma Chung Malang \\ Email: reezm17@gmail.com \\ Yudhi Kurniawan \\ Fakultas Sains dan Teknologi, Program Studi Sistem Informasi \\ Universitas Ma Chung Malang \\ Email: yudhi.kurniawan@machung.ac.id
}

\begin{abstract}
ABSTRAK
Universitas atau perguruan tinggi memiliki proses bisnis utama yaitu proses bisnis akademik yang meliputi proses penerimaan mahasiswa baru, perkuliahan, hingga kelulusan mahasiswa. Setiap proses tersebut mengelola banyak data dan informasi serta melibatkan beberapa entitas dalam menjalankannya. Pemanfaatan teknologi informasi akan membantu proses menjadi lebih efektif dan efisien. Dalam pemanfaatan teknologi informasi tersebut dibutuhkan analisis terhadap kebutuhan perangkat lunak yang akan dikembangkan. Kebutuhan-kebutuhan tersebut membutuhkan dokumentasi yang praktis yang dapat digunakan sebagai acuan pengembangan. Penelitian kali ini menggunakan objek studi Universitas Ma Chung Malang. Metodologi yang digunakan mengacu konsep pendokumentasian kebutuhan perangkat lunak berstandar internasional yaitu ISO/IEC/IEEE 29148-2011. Standar ini membantu memaparkan hasil analisis kondisi saat ini dan penulisan spesifikasi kebutuhan perangkat lunak (SRS) yang dilengkapi dengan pemodelan sistem menggunakan UML. SRS ini akan menjadi acuan para pengembang (developer) dalam mengembangan sebuah sistem.
\end{abstract}

Kata kunci: sistem informasi, sistem informasi akademik, spesifikasi kebutuhan perangkat lunak (SRS), ISO/IEC/IEEE 29148-2011, UML.

\begin{abstract}
University or college has a major business process, it is academic business process that includes admissions prosses of new student, study, until graduation. Each of these processes to manage a lot of data and information also involving several entities to implement it. By using information technology will help the process become more effective and efficient. In the utilization of information technology needs analysis of the software requirements to be developed. These reqirements requires practical documentation that can be used as a reference for the development. The study object in this research was in Universitas Ma Chung, Malang. The methodology used refers to documentations concept software requirements of international standards such as ISO/IEC/IEEE 29148-2011. This standard helps explain the analysis result of currently conditions and writing the software requirements specification (SRS) which is equipped with a modelling system using UML. SRS will be a reference for developers in a system development.
\end{abstract}

Keywords: information systems, academic information systems, software requirements specification (SRS), ISO/IEC/IEEE 29148-2011, UML.

\section{PENDAHULUAN}

Setiap universitas atau perguruan tinggi memiliki unit kerja yang saling terkait pada proses bisnisnya seperti unit keuangan, sumber daya manusia, perpustakaan, penjaminan mutu, pemasaran (marketing), kemahasiswaan, dan manajemen sarana dan prasarana. Setiap proses pada unit-unit tersebut memerlukan sebuah sistem agar berjalan sesuai dengan kebutuhan, yaitu sistem yang dapat menyediakan dan menghasilkan informasi yang transparan dan akurat serta mempermudah pekerjaan yang dilakukan. Proses bisnis yang menjadi salah satu bagian terpenting dari universitas adalah proses bisnis akademik yang dimulai dari proses pendaftaran mahasiswa baru, proses belajar mengajar, hingga yang paling 
terakhir adalah proses kelulusan. Untuk menjalankan proses-proses tersebut diperlukan sebuah sistem informasi akademik.

Sistem informasi akademik yang akan dibangun diharapkan dapat menjaga tingkat akurasi data dan membantu mempercepat pekerjaan pengguna baik mahasiswa, staf, dan dosen dalam setiap aktivitas yang dilakukan. Dalam pembangunan dan pengembangan sistem informasi tentunya harus melewati beberapa tahapan umum, mulai dari analisis, desain, coding, pengujian (testing), hingga implementasi. Pembangunan dan pengembangan pada tahap awal tidak akan melewatkan tahapan analisis, karena pada tahap ini akan secara detil dibahas mengenai masalah yang terjadi hingga spesifikasi kebutuhan (requirement) apa saja yang diperlukan untuk menghasilkan perangkat lunak (software) pada sistem informasi yang sesuai, untuk selanjutnya disingkat SRS (software requirement specification). SRS akan membantu para pengembang (developer) dalam pembangunan sistem informasi.

Universitas Ma Chung merupakan salah satu universitas yang memiliki sistem informasi akademik. Sistem ini akan digunakan untuk mengelola dan menyediakan informasi-informasi yang dibutuhkan selama masa belajar hingga tahap kelulusan. Informasi yang disediakan misalnya informasi matakuliah, nilai, poin keaktifan, keuangan, dan tugas-tugas. Namun saat ini sistem ini belum terbangun secara efisien dan efektif sehingga informasi yang disediakan masih belum memenuhi kebutuhan pengguna. Beberapa informasi tersebut misalnya, informasi yang diberikan untuk mahasiswa seperti data diri belum sesuai dengan keadaan asli mahasiswa, informasi matakuliah saat proses KRS (Kartu Rencana Studi) online juga belum sepenuhnya diberikan sesuai dengan kebutuhan mahasiswa, dan informasi pembayaran tagihan keuangan mahasiswa yang masih diperbarui manual oleh bagian administrasi keuangan. Oleh karena itu, dibutuhkan analisis ulang berkaitan dengan kesesuaian antara kebutuhan pengguna dengan ketersediaan informasi dan fungsi pada sistem. Analisis ini nantinya akan menghasilkan spesifikasi kebutuhan sistem sesuai dengan kebutuhan dan perilaku pengguna. Hasil analisis tersebut akan dituliskan dalam sebuah dokumen SRS. Dalam penelitian kali ini, dokumentasi SRS akan dipaparkan mengikuti standar internasional ISO/IEC/IEEE 29148-2911, tentang System and Software Engineering - Life Cycle Processes - Requirements Engineering. Standar ini merupakan sebuah praktik untuk menjelaskan secara detil proses membangun sistem informasi melalui pendekatan spesifikasi perangkat lunak.

\section{METODOLOGI PENELITIAN}

Metode penelitian yang yang digunakan meliputi konsep, alur atau urutan, dan jadwal pengerjaan dari penelitian. Penelitian akan fokus pada penyusunan dokumen spesifikasi kebutuhan perangkat lunak (SRS) yang dilakukan melalui beberapa tahap pada alur penelitian dengan menyesuaikan jadwal yang sudah dibuat. Penyusunan dokumen ini akan dipaparkan sesuai dengan standar penulisan dokumen SRS pada ISO/IEC/IEEE 29148-2011.

\subsection{Konsep Penelitian}

Penelitian diawali dengan melakukan analisis penggunaan sistem informasi akademik saat ini oleh masing-masing pengguna yang terlibat. Kemudian tahap berikutnya adalah melakukan proses pengelolaan data dan informasi yang diperoleh dari analisis tahap pertama. Analisis ini akan dipaparkan sesuai dengan standar penulisan dokumen SRS ISO/IEC/IEEE 29148-2011. Pemaparan ini mencakup 3 area, yaitu organizational environment, business operation, dan system operation. Pada area pertama yaitu organizational environment akan dijelaskan informasi kebutuhan stakeholder, sedangkan pada area business operation akan dijelaskan proses bisnis sistem informasi akademik universitas, dan pada area system operation akan dijelaskan kebutuhan sistem informasi akademik. Berdasarkan hasil pengelolaan informasi-informasi tersebut maka akan diarahkan untuk tahap berikutnya yaitu pendokumentasian SRS. Penulisan dokumentasi ini juga mengacu pada penulisan SRS yang ada pada ISO/IEC/IEEE 29148-2011 pada bagian Software Requirement Specificstion (SRS) document.

\subsection{Alur Penelitian}

Alur penelitian yang dilakukan dalam penelitian ini dimulai dari tahap memahami dan merumuskan masalah yang akan dibahas, setelah itu melakukan tahap studi literatur yang sesuai dengan topik penelitian yang dilakukan. Studi literatur adalah metode pendalaman materi dengan cara membaca, mencari, memahami, serta meringkas hal-hal yang berhubungan dengan penelitian ini. Adapun sumber yang digunakan adalah buku dan media online seperti website dan jurnal online. Tahap berikutnya adalah menentukan apa saja variabel dan objek yang dibutuhkan dalam penelitian. Setelah itu, dilakukan pengumpulan data berdasarkan variabel dan objek tersebut untuk berikutnya dilakukan analisis. Pengumpulan data dilakukan dengan dua cara, yaitu wawancara dan tinjauan data dan dokumen. 
Wawancara dilakukan dengan sasaran atau subyek semua pihak yang mewakili dari setiap unit terkait di Universitas Ma Chung. Sedangkan tinjauan data dan dokumen dilakukan dengan cara pengumpulan data berdasarkan data dan dokumen yang dikumpulkan dari pihak-pihak terkait sebagai pendukung pengisian dokumen SRS.

Tahap terakhir dari penelitian adalah membuat kesimpulan dan saran dari proses penelitian yang dilakukan. Sejalan dengan tahap penentuan variabel dan objek, pengumpulan data, serta analisis data, akan dilakukan proses pendokumentasian sesuai dengan standar penulisan yang digunakan dalam penelitian ini yaitu standar dokumentasi ISO/IEC/IEEE 29148-2011.

\section{HASIL DAN PEMBAHASAN}

Pemaparan hasil analisis penggunaan sistem informasi akademik yang sedang berjalan dapat digunakan sebagai masukan dalam pembuatan dokumen SRS yang meliputi informasi mengenai kebutuhan stakeholders dan kebutuhan sistem terhadap produk (software) sistem informasi akademik yang akan dikembangkan. Sedangkan untuk pemaparan dokumen SRS mengambil beberapa bagian (item) pada prototype SRS outline yang ada pada ISO/IEC/IEEE 29148-2911 dan disesuaikan dengan permintaan kebutuhan UPT Sistem Informasi sebagai pengembang sistem informasi akademik Universitas Ma Chung. Bagian-bagian tersebut meliputi:

1) Introduction

a. Purpose

b. Scope

c. Product overview: (1) Product perspective, (2) Product functions, (3) User characteristics, (4) Limitations

2) References

3) Spesific Requirements

a. Functions

b. Non functional requirements

Dalam non functional requirement dibahas mengenai usability, performance, software systemj attribute, atau supporting information jika memang diperlukan.

c. Functional requirements

Functional requirement sebenarnya termasuk dalam paparan bagian function, namun untuk memudahkan membaca hasil dari functional requirement dibuatkan sub function atau bagian sendiri.

d. Logical database

4) Appendices: Assumptions and dependencies

\subsection{Informasi Kebutuhan Stakeholders}

Informasi kebutuhan stakeholders meliputi stakeholders, business structure, business process, dan user requirement. Bagian-bagian ini diperlukan karena memiliki keterkaitan dan menjadi salah satu sumber informasi kebutuhan dalam penyusunan informasi pada dokumen spesifikasi kebutuhan perangkat lunak (SRS).

\subsubsection{Stakeholders}

Stakeholders terkait pengembangan sistem informasi akademik Universitas Ma Chung disesuaikan dengan area atau entitas yang berelasi dalam proses bisnis akademik (lihat gambar 2). Stakeholders tersebut didefinisikan sebagai pengguna sistem yang meliputi bagian pemasaran (admisi termasuk dalam pemasaran), administrasi akademik, administrasi keuangan mahasiswa, sekretaris fakultas, program studi, dosen, dosen PA, UPT perpustakaan, pengelolaan dan pemeliharaan aset, layanan sertifikasi, kemahasiswaan, pusat karir dan alumin, mahasiswa, dan calon mahasiswa.

\subsubsection{Business Structure}

Stakeholders (pengguna sistem) yang dijelaskan sebelumnya juga merupakan bagian dari unit-unit pada struktur organisasi Universitas Ma Chung seperti pada gambar 1. 


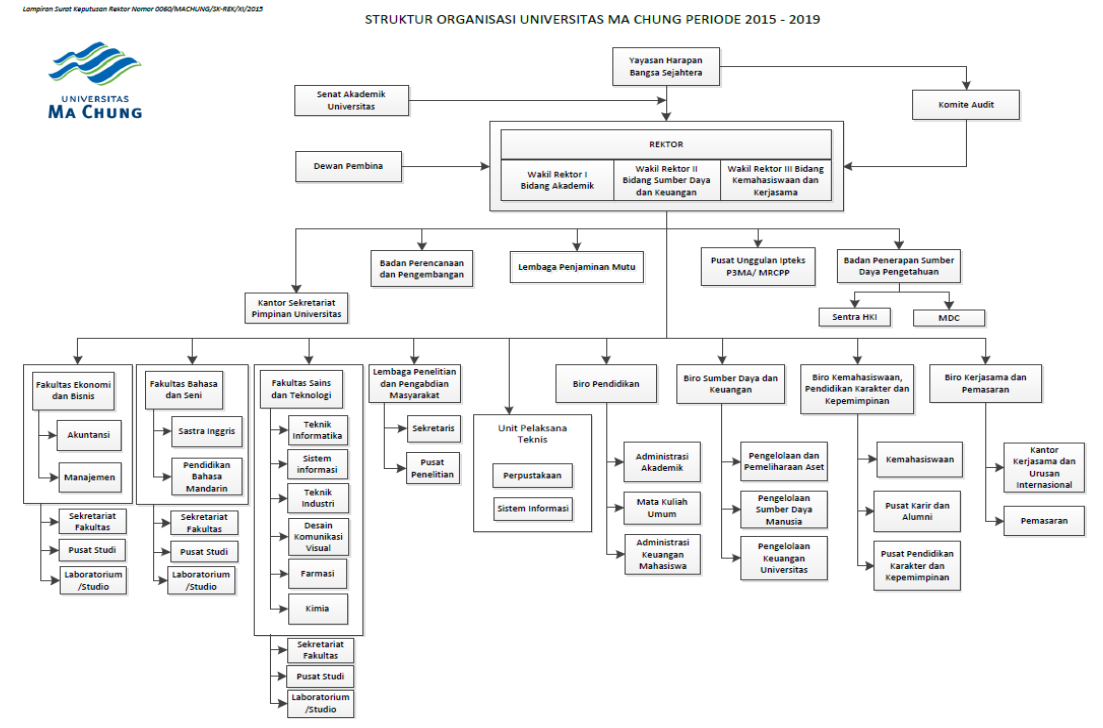

Gambar 1. Struktur Organisasi Universitas Ma Chung Malang

\subsubsection{Business Process}

Proses bisnis ini menggambarkan serangkaian alur yang bisa dilakukan sistem dalam setiap aktivitas bisnis akademik. Gambar 2 menjelaskan alur proses bisnis utama pada kegiatan akademik Universitas Ma Chung saat ini mulai dari penerimaan mahasiswa baru, proses pengajaran, hingga kelulusan.

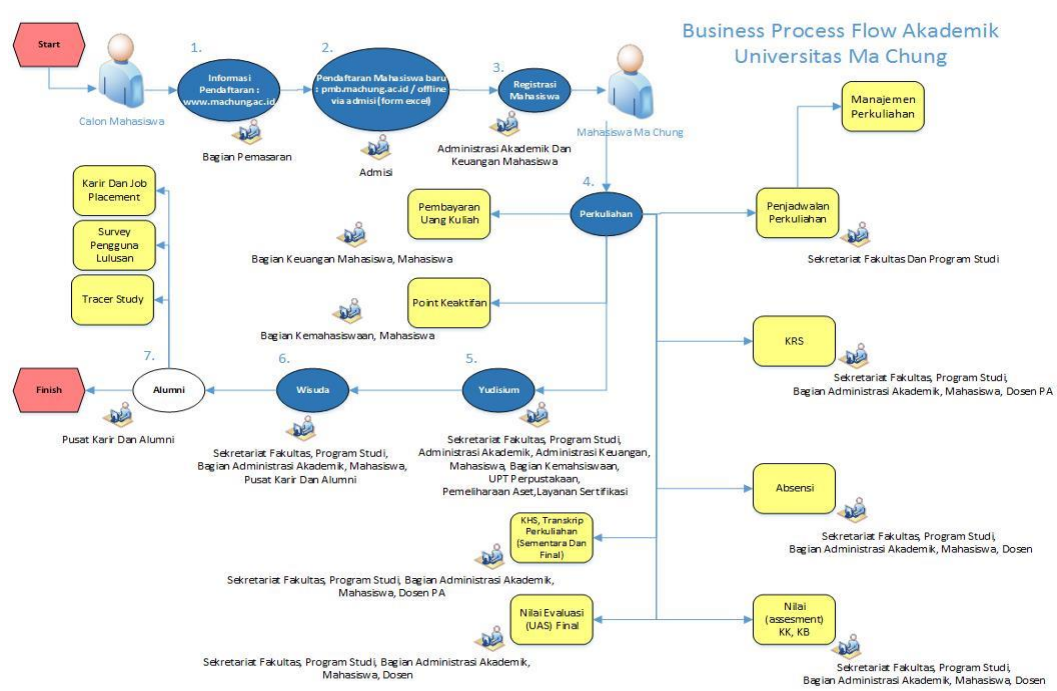

Gambar 2. Proses Bisnis Sistem Informasi Akademik Universitas Ma Chung (UPT Sistem Informasi)

\subsubsection{User Requirements}

Pengguna (user) disesuaikan berdasarkan stakeholders yang dijelaskan sebelumnya pada poin 3.1.1. Masing-masing pengguna akan melakukan aktivitas dalam setiap proses bisnis. Aktivitas-aktivitas tersebut memiliki kebutuhan data dan informasi yang diperlukan dalam pengelolaan sistem informasi akademik. Seperti contoh Tabel 1 yaitu kebutuhan data dan informasi untuk bagian pemasaran. 
Tabel 1. Daftar kebutuhan pengguna sistem

\begin{tabular}{cll}
\hline Pengguna & \multicolumn{1}{c}{ Proses/Aktivitas } & Data dan Informasi yang Diperlukan \\
\hline \multirow{6}{*}{ Pemasaran } & Memasuk-kan informasi ke & -Prosedur pendaftaran \\
& website & -Informasi penerimaan mahasiswa baru \\
& Memasukkan data pndaftar & -Informasi beasiswa \\
& Melakukan seleksi & -Informasi biaya studi \\
& Mengumumkan hasil seleksi & -Data pendaftar (calon mahasiswa) \\
& \multirow{6}{*}{ Penerbitan SKR } & -Kriteria dan syarat pendaftaran \\
& & -Data pendaftar (calon mahasiswa) \\
& & -Datil seleksi calon mahasiswa \\
& & -Biaya selama studi \\
\hline
\end{tabular}

\subsection{Informasi Kebutuhan Sistem}

Informasi kebutuhan sistem meliputi system function, dan functional requirement. Bagian-bagian ini diperlukan karena memiliki keterkaitan dengan penyusunan informasi pada dokumen spesifikasi kebutuhan perangkat lunak (SRS).

\subsubsection{System Function}

Fungsi utama sistem informasi akademik yang akan dikembangkan adalah untuk menangani proses akademik mulai dari proses penerimaan mahasiswa baru, proses belajar-mengajar, hingga kelulusan dengan memanfaatkan teknologi informasi serta memenuhi kebutuhan data dan informasi oleh stakeholders seperti yang dijelaskan pada poin 3.1.4.

\subsubsection{Functional Requirements}

Kebutuhan fungsional merupakan jenis kebutuhan yang berisi pendefinisian layanan yang harus disediakan, bagaimana reaksi sistem terhadap input dan apa yang harus dilakukan sistem dalam situasi khusus. Adapun kebutuhan fungsional pada sistem ini dipaparkan pada poin 3.3 sub bab Functional Requirements yang disesuaikan dengan kebutuhan data dan informasi stakeholders serta diklasifikasikan berdasarkan masing-masing kegiatan pada proses bisnis utama Universitas Ma Chung Malang.

\subsection{Spesfikasi Kebutuhan Perangkat Lunak (SRS) Sistem Informasi Akademik}

Spesifikasi kebutuhan perangkat lunak sistem informasi akademik Universitas Ma Chung Malang yang mengacu pada standar ISO/IEC/IEEE 29148-2011 pada bagian Software Requirement Specification (SRS) document. dipaparkan berdasarkan modul-modul pada sistem informasi akademik universitas yang dijelaskan pada proses bisnis Gambar 2. Modul-modul tersebut meliputi modul informasi pendaftaran, pendaftaran mahasiswa baru, registrasi mahasiswa, perkuliahan (penjadwalan perkuliahan, KRS, absensi, nilai, KHS dan transkrip, pembayaran keuangan, dan poin keaktifan), yudisium, dan wisuda. Berikut adalah hasil dokumen SRS untuk modul informasi pendaftaran, lima modul lainnya dipaparkan dalam dokumen terpisah.

\subsubsection{Introduction}

1) Purpose

Tujuan pembuatan modul ini adalah untuk membantu pengembangan fitur-fitur dalam pencarian informasi-informasi mengenai pendaftaran mahasiswa baru pada website Universtas Ma Chung.

2) Scope

Ruang lingkup dalam pengembangan modul ini membahas mengenai kebutuhan perangkat lunak sistem informasi akademik pada bagian informasi pendaftaran mahasiswa baru.

3) Product Overview

a) Product Perspective

Sistem informasi akademik modul informasi pendaftaran merupakan bagian dari proses bisnis penerimaan mahasiswa baru. Modul ini memiliki keterkaitan dengan modul pendaftaran mahasiswa baru. 
b) Product Functions

Fungsi utama dari penggunaan modul ini adalah untuk memberikan informasi-informasi mengenai pendaftaran mahasiswa baru pada website universitas dan menjelaskan bagaimana hubungan antara calon mahasiswa baru (pendaftar) dengan bagian pemasaran dalam menggunakan sarana website yang disediakan.

4) User Characteristics

Pada bagian ini akan dijelaskan siapa saja pengguna (user) dalam modul ini. Pengguna tersebut diantaranya adalah Bagian Pemasaran (P2) dan Calon Mahasiswa Baru (P1).

5) Limitations

Modul ini membahas bagaimana sistem mengelola informasi pendaftaran yang akan diakses oleh pengguna yaitu pendaftar dan bagian pemasaran, serta menyediakan link untuk membuka formulir pendaftaran online.

\subsubsection{Specific Requirements}

1) Functions

Aktifitas atau fungsi yang dilakukan oleh pengguna untuk memproses input pada sistem agar menghasilkan output yang diinginkan digambarkan dalam use case diagram (Gambar 3) dan activity diagram (Gambar 4).

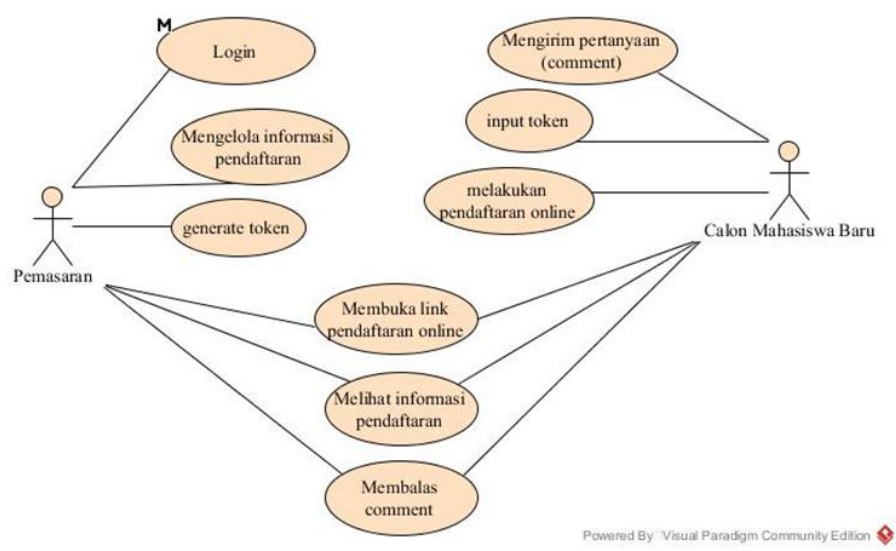

Gambar 3. Use Case Diagram Modul Informasi Pendaftaran

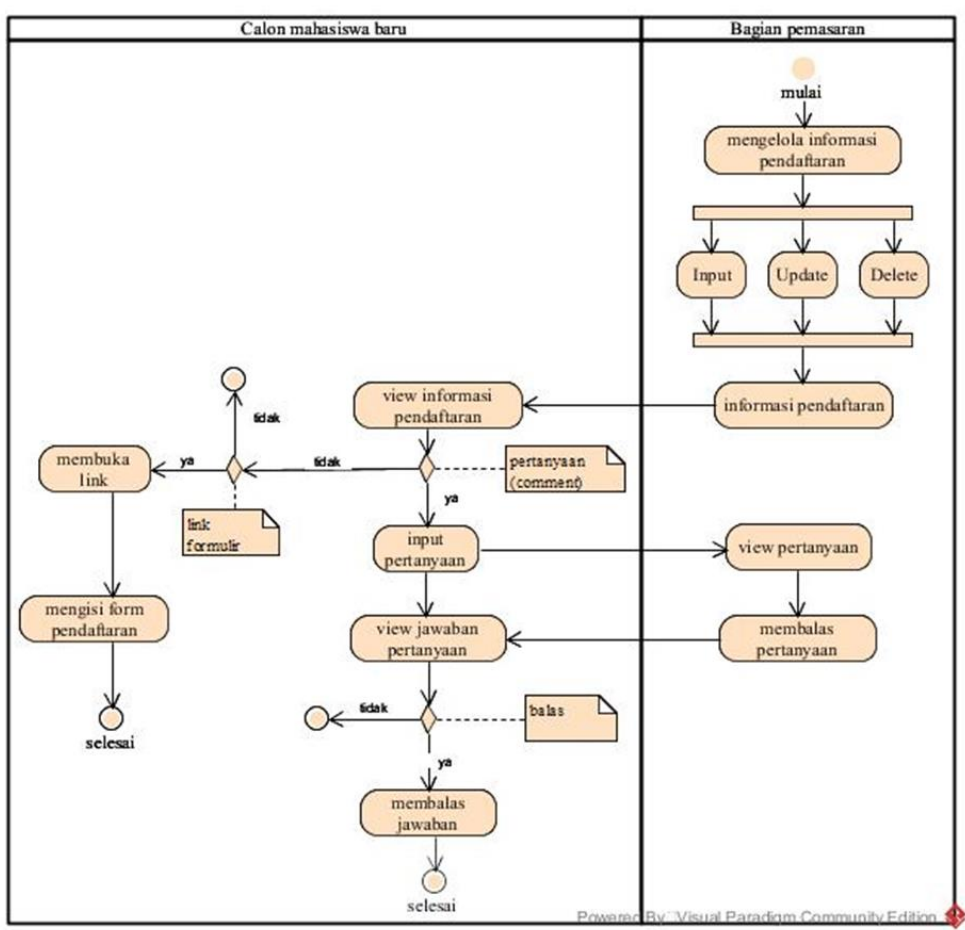

Gambar 4. Activity Diagram Modul Informasi Pendaftaran 
2) Non Functional Requirements

Tabel 2. Non functional requirements

\begin{tabular}{|c|c|c|}
\hline No & Deskripsi Kebutuhan & Keterangan \\
\hline 1 & $\begin{array}{l}\text { Sistem dapat diakses pada seluruh platform dan } \\
\text { device secara online }\end{array}$ & \\
\hline
\end{tabular}

3) Functional Requirements

Tabel 3. Functional requirements

\begin{tabular}{|c|c|c|c|c|}
\hline \multirow{2}{*}{ No } & \multirow{2}{*}{$\begin{array}{l}\text { Kode } \\
\text { User }\end{array}$} & \multirow{2}{*}{ Deskripsi Kebutuhan } & \multicolumn{2}{|c|}{ Fungsional } \\
\hline & & & User & Sistem \\
\hline 1 & $\mathrm{P} 1, \mathrm{P} 2$ & Pengguna dapat melihat informasi pendaftaran & $\mathrm{V}$ & \\
\hline 2 & $\mathrm{P} 1$ & $\begin{array}{l}\text { Pengguna dapat mengirim pertanyaan (comment) } \\
\text { mengenai informasi pendaftaran }\end{array}$ & V & \\
\hline 3 & $\mathrm{P} 1, \mathrm{P} 2$ & Pengguna dapat membalas comment & $\mathrm{V}$ & \\
\hline 4 & $\mathrm{P} 1, \mathrm{P} 2$ & Pengguna dapat membuka link pendaftaran online & $\mathrm{V}$ & \\
\hline 5 & $\mathrm{P} 2$ & $\begin{array}{l}\text { Pengguna dapat melakukan pengelolaan informasi } \\
\text { pendaftaran }\end{array}$ & $\mathrm{V}$ & \\
\hline 6 & $\mathrm{P} 1, \mathrm{P} 2$ & $\begin{array}{l}\text { Pengguna dapat memasukan data referensi/ sekolah untuk } \\
\text { digunakan pendaftar }\end{array}$ & $\mathrm{V}$ & \\
\hline 7 & $\mathrm{P} 2$ & $\begin{array}{l}\text { Pengguna dapat mengirim email kepada pendaftar (calom } \\
\text { mahasiswa baru) }\end{array}$ & $\mathrm{V}$ & \\
\hline 8 & $\mathrm{P} 1$ & $\begin{array}{l}\text { Pengguna dapat memasukkan data pendaftaran secara } \\
\text { online }\end{array}$ & $\mathrm{V}$ & \\
\hline 9 & $\mathrm{P} 2$ & Pengguna dapat menggunakan key untuk daftar online & $\mathrm{V}$ & \\
\hline 10 & $\mathrm{P} 1$ & Pengguna dapat mengunggah beberapa file yang diminta & $\mathrm{V}$ & \\
\hline 11 & P1 & $\begin{array}{l}\text { Pengguna dapat memberikan pilihan referensi dari siapa } \\
\text { ketika mendaftar online }\end{array}$ & $\mathrm{V}$ & \\
\hline 12 & & Sistem dapat mengenerate token untuk pendaftaran & & $\mathrm{V}$ \\
\hline 13 & & Sistem dapat menampilkan informasi pendaftaran & & $\mathrm{V}$ \\
\hline 14 & & Sistem dapat menerima input informasi pendaftaran & & $\mathrm{V}$ \\
\hline 15 & & Sistem dapat menerima update informasi pendaftaran & & $\mathrm{V}$ \\
\hline 16 & & $\begin{array}{l}\text { Sistem dapat menampilkan pertanyaan (comment) } \\
\text { mengenai informasi pendaftaran }\end{array}$ & & $\mathrm{V}$ \\
\hline 17 & & $\begin{array}{l}\text { Sistem dapat membalas comment mengenai informasi } \\
\text { pendaftaran }\end{array}$ & & $\mathrm{V}$ \\
\hline 18 & & $\begin{array}{l}\text { Sistem dapat menerima update comment mengenai } \\
\text { informasi pendaftaran }\end{array}$ & & $\mathrm{V}$ \\
\hline 19 & & Sistem dapat menampilkan notifikasi new comment & & V \\
\hline 20 & & Sistem dapat menampilkan link pendaftaran online & & $\mathrm{V}$ \\
\hline
\end{tabular}

4) Logical Database Requirements

Logical database requirements dipaparkan dalam bentuk class diagram seperti pada Gambar 5.

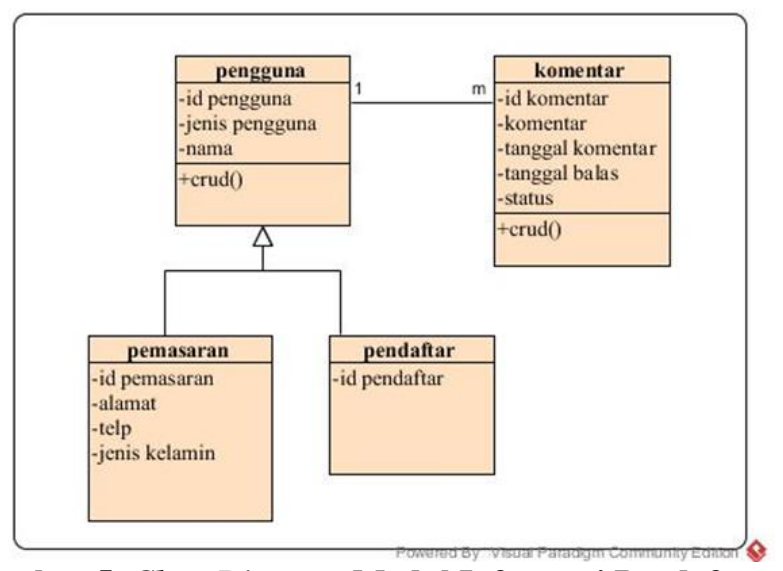

Gambar 5. Class Diagram Modul Informasi Pendaftaran 


\subsubsection{Appendices}

Asumsi dan ketergantungan yang terdapat pada modul ini, sebagai berikut.

(1) Modul informasi pendaftaran ini diasumsikan dapat dikonsumsi oleh calon mahasiswa baru (pendaftar) yang sedang mencari informasi mengenai pendaftaran mahasiswa baru di Universitas Ma Chung Malang.

(2) Informasi-informasi pendaftaran dapat diakses secara online melalui website universitas.

(3) Interaksi antar pengguna yaitu pendaftar dan bagian pemasaran yaitu dengan menggunakan website pada fitur comment.

(4) Pendaftar harus memiliki chatting dan email token/key sebelum mengisi formulir pendaftaran online.

\section{KESIMPULAN}

Berdasarkan hasil dan pembahasan dapat disimpulkan bahwa kondisi sistem informasi akademik Universitas Ma Chung saat ini belum bisa memenuhi kebutuhan pengguna secara menyeluruh, maka dibutuhkan analisis ulang dalam pembangunan sistem informasi tersebut yang berkaitan dengan kesesuaian antara kebutuhan pengguna dengan ketersediaan informasi dan fungsi pada sistem. Analisis ini nantinya akan menghasilkan spesifikasi kebutuhan sistem sesuai dengan kebutuhan dan perilaku pengguna. Hasil analisis tersebut akan dituliskan dalam sebuah dokumen spesifikasi kebutuhan perangkat lunak (SRS). SRS ini didokumentasikan dengan mengacu pada standar internasional penulisan dokumen SRS yaitu ISO/IEC/IEEE 29148-2011 yang didalamnya juga dijelaskan pemodelan sistem menggunakan UML agar lebih mudah dipahami oleh seorang developer.

\section{DAFTAR PUSTAKA}

[1] Borque, P., \& Fairley, R. (2014). Guide to the Software Engineering Body of Knowledge Version 3.0. IEEE Computer Society Staff.

[2] Gunawan, I. A. (2012). Rancang Bangung Sistem Informasi Kontrol Lalu Lintas Kota Denpasar. Denpasar: Teknik Informatika, Universitas Udayana.

[3] IEEE Std 830-1998. (1998). IEEE Recommended Practice for Software Requirement Spesification. New York: The Institute of Electrical ana Electronics Engineers, Inc.

[4] ISO/IEC/IEEE 29148. (2011, Desember 01). Systems and Software Engineering - Life Cycle Processes - Requirements Engineering.

[5] J, W., \& J, P. (2002). Strategic Planning For Information System, 3e. United Kingdom: 90 Tottenham Court Road

[6] Kendall, K. E., \& Kendall, J. E. (2006). Systems Analysis And Design, 8e. United States: Prentice Hall.

[7] Sun, B.Sc., H. (2007). Developing User-Centric Software Requirements Specifications. China: Nankai University.

[8] Universitas Ma Chung. (2015). Keputusan Rektor Universitas Ma Chung 0060/Ma Chung/SKREK/XI/2015 Tentang Organisasi dan Tata Kerja Di Lingkungan Universitas Ma Chung. Malang: Universtas Ma Chung. 